\title{
PERLAKUAN PERMUKAAN PADA ROLLER RANTAI DENGAN METODE PLASMA CARBURIZING DARI CAMPURAN GAS He DAN $\mathrm{CH}_{4}$ PADA TEKANAN 1,8 mbar
}

\author{
Dwi Priyantoro $^{1}$, Tjipto Sujitno ${ }^{2}$, Bangun Pribadi ${ }^{1}$, Zuhdi Arif Ainun Najib ${ }^{1}$ \\ 1) Sekolah Tinggi Teknologi Nuklir, BATAN, Yogyakarta, Indonesia \\ 2) Pusat Sains dan Teknologi Akselerator, BATAN, Yogyakarta, Indonesia
}

\begin{abstract}
ABSTRAK
PERLAKUAN PERMUKAAN PADA ROLLER RANTAI DENGAN METODE PLASMA CARBURIZING DARI CAMPURAN GAS He DAN $\mathrm{CH}_{4}$ PADA TEKANAN 1,8 mbar. Transmisi daya mekanik antara dua roda gigi dapat menggunakan rantai. Bagian dari mata rantai yang bergesekan langsung dengan roda gigi adalah roller rantai. Permukaan roller rantai harus memiliki sifat yang keras agar tidak mudah aus. Pengerasan permukaan roller rantai dapat dilakukan dengan pembentukan lapisan DLC pada permukaan tersebut. Lapisan DLC dapat dibentuk dengan metode plasma carburizing. Plasma carburizing dalam penelitian ini memanfaatkan lucutan pijar DC dari campuran gas helium dan gas metana pada tekanan 1,8 mbar dan temperatur $573 \mathrm{~K}$, sedangkan waktu perlakuan bervariasi 1, 2, 3, 4, dan 5 jam. Hasil penelitian menunjukkan bahwa kekerasan permukaan roller rantai naik dari 276,05 VHN menjadi 403,56 VHN atau terjadi kenaikan sebesar 46,19\% setelah dilakukan perlakuan plasma carburizing selama 4 jam.
\end{abstract}

Kata kunci: DLC, plasma carburizing, roller rantai

\begin{abstract}
SURFACE TREATMENT AT ROLLER CHAIN BY PLASMA CARBURIZING METHOD USING GASEOUS MIXTURE OF He AND $\mathrm{CH}_{4}$ ON PRESSURE 1.8 mbar. Mechanical power transmission between two gears can use a chain. The chain part that directly rubs against the gears is the roller chain. The surface of the roller chain must have properties that do not easily wear out. Chain roller surface hardening can be done by forming DLC (Diamond Like Carbon) coating on the surface. DLC layer can be formed by plasma carburizing method. In this study, plasma carburizing utilized DC glow discharge of a gaseous mixture of helium and methane under pressure of 1.8 mbar and temperature of $573 \mathrm{~K}$, while the treatment time varied 1, 2, 3, 4, and 5 hours. The results showed that the surface hardness of roller chain increased from 276.05 VHN to 403.56 VHN or equaled to $46.19 \%$, after 4 hours of treatment.
\end{abstract}

Keywords: DLC, plasma carburizing, chain roller

\section{PENDAHULUAN}

Rantai sering digunakan untuk transmisi daya mekanis [1,2] antar-dua roda gigi. Sebuah rantai, seperti tertera pada Gambar 1, tersusun atas beberapa mata rantai yang saling bersambungan. Bagian dari mata rantai yang bersinggungan langsung dengan roda gigi adalah roller rantai. Roller rantai menumpu beban gesek yang tinggi, oleh karena itu harus memiliki sifat yang keras [1] agar tidak mudah aus. 

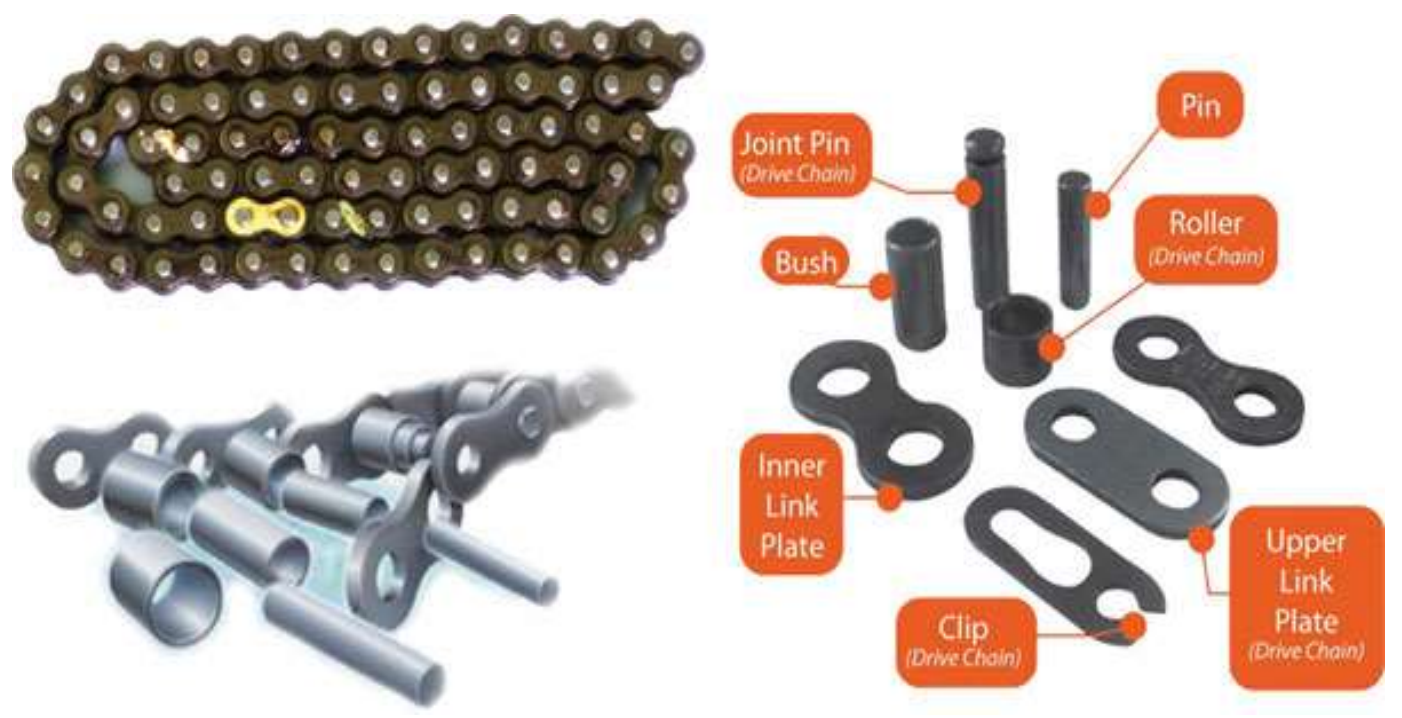

Gambar 1. Bagian-Bagian Rantai [2]

Memperkeras permukaan roller [2] rantai dapat dilakukan dengan membentuk lapisan DLC (diamond like carbon) pada permukaan tersebut. Proses pengerasan seperti ini termasuk kategori surface treatment [3]. Dalam proses ini perubahan sifat hanya terjadi pada permukaan, sedangkan bagian dalam tidak mengalami perubahan sifat. Lapisan DLC [2,4,5] memiliki sifat keras sehingga apabila dilapiskan pada roller rantai, umur pakai rantai dapat lebih panjang.
Lapisan DLC dapat dibentuk dengan metode plasma carburizing [2] lucutan pijar DC dari campuran gas helium dan gas metana. Alat yang digunakan adalah reaktor plasma. Skema reaktor plasma lucutan pijar DC terlihat pada Gambar 2. Komporen utama reaktor plasma [2,6] adalah tabung plasma yang dilengkapi dengan sumber tegangan DC, sumber gas helium dan metana, dan pompa hampa. Dalam tabung plasma terdapat anoda dan katoda. Benda kerja atau sering disebut substrat/sampel diletakkan pada katoda.

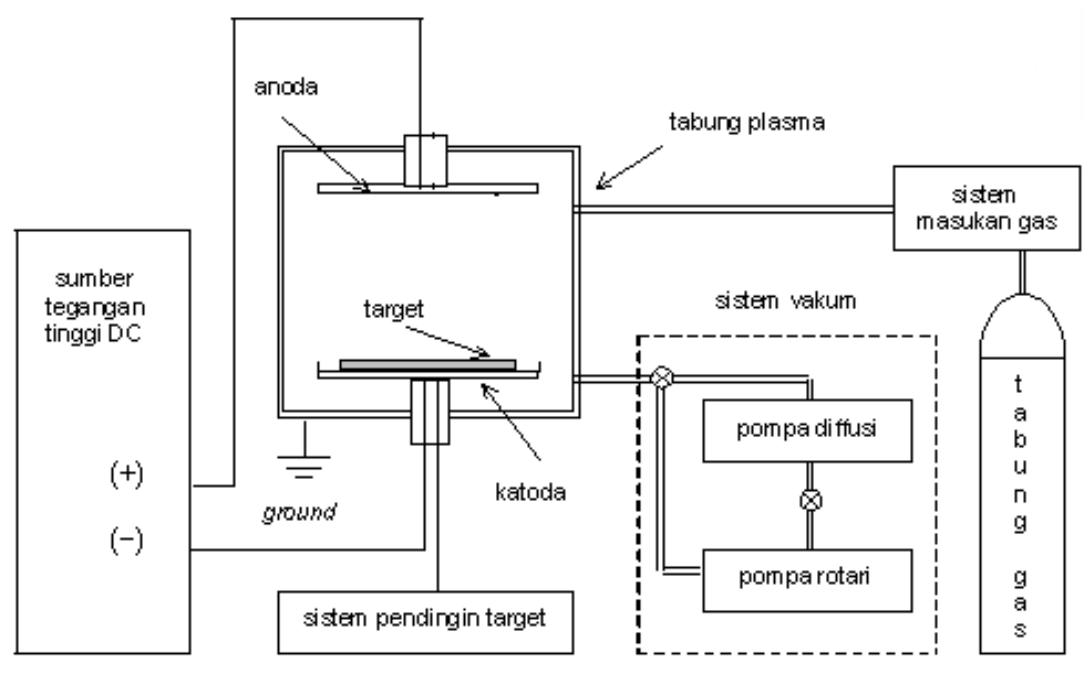

Gambar 2. Skema Reaktor Plasma [2,6]

Proses pembentukan lapisan DLC [2,6] adalah sebagai berikut. Mula-mula benda kerja diletakkan pada katoda. Selanjutnya, tabung plasma dihampakan, lalu diisi campuran gas helium dan gas metana pada tekanan rendah (1,8 mbar). Kemudian tabung plasma diberi tegangan DC melalui anoda dan katoda. Temperatur plasma $[2,6]$ diatur sebesar $573 \mathrm{~K}$, dengan mengatur tegangan anoda-katoda. Dengan adanya tegangan ini maka terjadi lucutan elektron dari katoda menuju anoda. Elektron akan menumbuk partikel gas metana 
sehingga terionisasi membentuk ion positif dari karbon dalam fase plasma. Indikator terbentuknya plasma adalah adanya arus listrik yang mengalir lewat anoda-katoda.

Ion karbon dalam fase plasma ini akan terdeposisi pada permukaan benda kerja yang telah diletakkan pada katoda. Pendeposisian ini berlangsung terus-menerus sehingga terbentuk lapisan tipis yang disebut lapisan DLC. Lapisan ini memiliki sifat sangat keras $[2,4,5,6]$.

Kekerasan permukaan benda kerja dapat diukur dengan uji Vikers [2,6,7]. Pertambahan kekerasan permukaan dapat diketahui dari selisih antara kekerasan benda kerja sebelum dan setelah perlakuan plasma carburizing. Bila kekerasan permukaan material asli adalah $k_{0}$ dan kekerasan permukaan benda kerja setelah perlakuan plasma carburizing adalah $k_{1}$, maka kenaikan kekerasan $(\Delta k)$ adalah

$\Delta k=k_{1}-k_{0}$

atau peningkatan kekerasan $(\eta)$ adalah

$\eta=\frac{\Delta k}{k_{0}} \times 100 \%$

Untuk melihat keadaan kekerasan permukaan benda kerja yang dikenai perlakuan plasma carburizing, dibuat grafik kekerasan vs waktu. Dari grafik tersebut dapat diketahui kekerasan maksimum beserta lama waktu yang diperlukan untuk proses plasma carburizing.

\section{METODE PENELITIAN}

Pengerasan permukaan roller rantai dengan metode plasma carburizing [2,6]. Dalam penelitian ini digunakan campuran gas helium dan metana pada tekanan 1,8 mbar dan temperatur plasma $573 \mathrm{~K}$, dengan waktu perlakuan bervariasi: 1 jam, 2 jam, 3 jam, 4 jam, dan 5 jam. Selanjutnya hasil perlakuan plasma carburizing pada benda kerja diuji kekerasannya dengan alat uji Vikers. Urutan langkah penelitian $[2,6,7]$ dapat dilihat pada Gambar 3.

\section{Langkah 1. Penyiapan Substrat}

Mata rantai dibongkar dan diambil bagian roller rantai. Substrat atau benda kerja disiapkan dan dipisahkan ke dalam 6 (enam) kelompok, yaitu kelompok ke-1, ke-2, ke-3, ke-4, ke-5, dan ke-6. Benda kerja kelompok ke-1 sampai dengan ke-5 dikenai perlakuan plasma carburizing, sedangkan benda kerja kelompok ke-6 tidak dikenai perlakuan. Benda kerja kelompok ke-6 ini ditetapkan sebagai material asli.

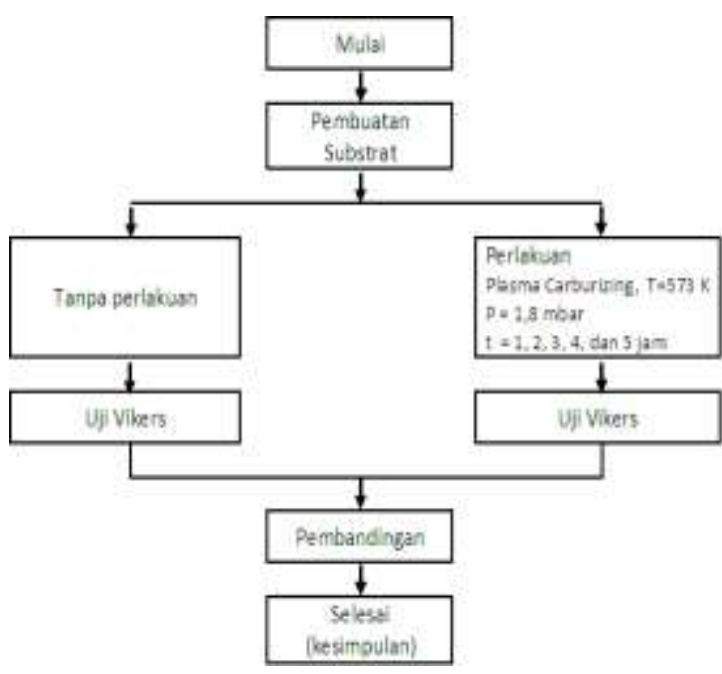

Gambar 3. Urutan Langkah Penelitian

\section{Langkah 2. Perlakuan Carburizing}

Reaktor plasma carburizing dioperasikan sesuai prosedur yang ada. Reaktor plasma diisi benda kerja ke-1, lalu dihampakan, kemudian diisi campuran gas helium dan metana pada tekanan rendah (1,8 mbar). Selanjutnya, reaktor plasma diberi tegangan tinggi pada anoda-katoda. Tekanan dipertahankan 1,8 mbar. Temperatur dinaikkan dari suhu kamar hingga $573 \mathrm{~K}$, dengan mengatur tegangan tinggi. Meter arus diamati, sebagai indikator terjadinya plasma carburizing. Kondisi perlakuan ini dipertahankan selama 1 (satu) jam. Selanjutnya reaktor plasma dihentikan, lalu didinginkan hingga suhu kamar dan benda kerja ke-1 diambil. Proses yang sama dilakukan terhadap benda kerja ke-2 dengan lama perlakuan 2 jam, benda kerja ke-3 dengan lama perlakuan 3 jam, benda kerja ke-4 dengan lama perlakuan 4 jam, dan benda kerja ke-5 dengan lama perlakuan 5 jam.

\section{Langkah 3. Pengujian Kekerasan}

Pengujian dikenakan pada semua benda kerja, baik yang mendapat perlakuan plasma carburizing (kelompok ke-1-5) maupun yang tidak mendapat perlakuan plasma carburizing (kelompok ke-6). Hasil pengujian dicatat sebagai hasil penelitian ini.

\section{Langkah 4. Pembandingan}

Pembandingan kekerasan dilakukan antara benda kerja yang telah dikenai perlakuan plasma carburizing dengan material asli. 
Dengan persamaan (1) dapat dihitung pertambahan kekerasan dan dengan persamaan (2) dapat dihitung persentase kenaikan kekerasan terhadap material asli. Selanjutnya dibuat grafik persentase kenaikan kekerasan vs waktu.

\section{HASIL DAN PEMBAHASAN}

Hasil penelitian ini tertera pada Tabel 1. Dalam Tabel 1 dimuat kekerasan lapisan DLC benda kerja kelompok ke-1 sampai dengan ke-5 beserta kekerasan benda kerja kelompok ke-6, yaitu material asli (tanpa perlakuan) dan juga kenaikan kekerasan yang dihitung sesuai persamaan (2).

Tabel 1. Kekerasan dan Kenaikan Kekerasan Benda Kerja

\begin{tabular}{ccc}
$\begin{array}{c}\text { Waktu } \\
\text { Perlakuan } \\
\text { (Jam) }\end{array}$ & $\begin{array}{c}\text { Kekerasan Lapisan } \\
\text { DLC (VHN) }\end{array}$ & $\begin{array}{c}\text { Kenaikan } \\
\text { Kekerasan (\%) }\end{array}$ \\
\hline 1 & 338,56 & 22,64 \\
2 & 342,87 & 22,21 \\
3 & 346,29 & 25,44 \\
4 & 403,56 & 46,19 \\
5 & 319,25 & 15,65 \\
\hline Tanpa & 276,05 & 0 \\
\hline perlakuan & & \\
\hline
\end{tabular}

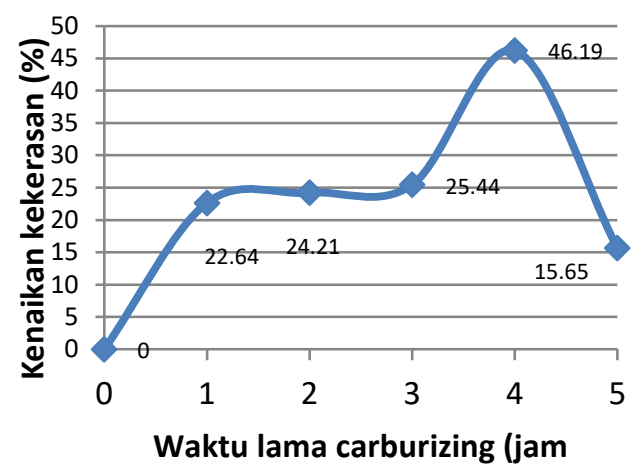

Gambar 4. Grafik Persentase Kenaikan Kekerasan vs Waktu

Dari Tabel 1 dapat dibuat grafik persentase kenaikan nilai kekerasan permukaan benda kerja sebagai fungsi dari waktu proses perlakuan plasma carburizing, seperti tertera pada Gambar 4.

Dari Gambar 4 tersebut dapat dilihat bahwa persentase kenaikan nilai kekerasan permukaan benda kerja cenderung naik sejalan dengan bertambahnya waktu perlakuan (yaitu plasma carburizing), dan nilai kekerasan cenderung menurun setelah mencapai titik maksimum. Nilai kekerasan berubah dari 276,05 VHN (material awal) menjadi 403,56 VHN (nilai maksimum), dengan waktu perlakuan selama 4 jam. Persentase kenaikan kekerasan adalah 46,19\%.

\section{KESIMPULAN}

Hasil penelitian menunjukkan bahwa kekerasan permukaan roller rantai naik dari 276,05 VHN menjadi 403,56 VHN setelah dilakukan plasma carburizing dengan waktu perlakuan selama 4 jam, atau terjadi kenaikan kekerasan sebesar 46,19\% dari material asli.

\section{SARAN}

Selain uji kekerasan, dipandang perlu dilakukan uji keausan.

\section{DAFTAR PUSTAKA}

1. Darwin Sebayang, Ir., 1981. Kekuatan Bahan. Jakarta: Erlangga.

2. Zuhdi Arif Ainun Najib, 2014. "Pengerasan Permukaan Mata Rantai dengan Plasma Lucutan Pijar DC dari Campuran Gas Helium dan Metana", dalam: Tugas Akhir STTN-BATAN. Yogyakarta.

3. Suprapto, Tjipto Suyitno, 2005. "Pengerasan Permukaan Baja St 42 dengan Teknik Nitridasi”, dalam: Puslitbang Teknologi Maju BATAN. Yogyakarta.

4. Sehah, 1997. "Pembuatan Lapisan Tipis Karbon Amorf Terhidrogenasi (a-C:H) dengan Teknik Plasma Lucutan Pijar RF'. Semarang: Undip.

5. Robertson, 2002. Diamond Like Amorphous Carbon. Cambridge: Cambridge University.

6. Anang Dwi Prasojo, 2014. "Optimasi Parameter Proses Pembentukan Lapisan Keras Permukaan Bush Rantai dengan Plasma Campuran Gas Helium-Metana", dalam: Tugas Akhir STTN-BATAN. Yogyakarta.

7. Bangkit Rahmat Hilca, 2012. "Plasma Nitrocarburizing pada Camshaft Tipe GLPro dan GL-100", dalam: Tugas Akhir STTN-BATAN. Yogyakarta. 